\title{
THINKING STYLE PREFERENCE, EMOTIONAL INTELLIGENCE AND LEADERSHIP EFFECTIVENESS
}

\author{
TESSIE H HERBST \\ Centre for Continuing Professional Development \\ Tshwane University of Technology \\ South Africa \\ KOBUS G MAREE \\ Faculty of Education \\ University of Pretoria \\ South Africa \\ Correspondence to: Tessie H Herbst \\ e-mail: herbstt@tut.ac.za
}

\begin{abstract}
In this study, the researchers investigate the relationship between thinking style preference, emotional intelligence and leadership effectiveness in an institution of higher education. The measuring instruments used were the Neethling Brain Preference Profile (NBPP) and the Mayer, Salovey and Caruso Emotional Intelligence Test (MSCEIT), as well as the Kouzes and Posner Leadership Practices Inventory (LPI) The sample comprised 138 managers within a higher education institution. The researchers found some evidence to support the relationship between thinking style, emotional intelligence (EI) and leadership effectiveness. The researchers concluded that facets of brain dominance and emotional intelligence may be potentially useful predictors of transformational leadership behaviours.
\end{abstract}

Keywords: thinking style, emotional intelligence, transformational leadership, brain dominance, brain hemisphericity

Leadership is a complex and diverse field of study. The difference between leaders and non-leaders remains a source of disagreement and controversy in the leadership domain (Herbst, Maree \& Sibanda, 2006). Zacarro, Kemp and Bader (2004) suggest that effective leaders differ from less effective leaders on a number of attributes, and that these differences contribute significantly to their effectiveness as leaders. They conclude: "Leader traits contribute significantly to the prediction of leader effectiveness, leader emergence, and leader advancement" (Zaccaro et al., 2004, p. 119).

Profound change and transformation in societies are well documented in management literature. Radical changes within the higher education environment, including restrictions on public spending, the new legislative framework, significant increases in enrolment, differentiation in the student population and globalisation called for universities to move from a traditional form of organisation to a more "entrepreneurial" model (Mignot-Gérard, 2003, p. 140). As a result, education systems in South Africa, like in many countries in Europe and elsewhere, are in the process of being reformed and restructured. These educational challenges are immense and have put immense pressure on institutions to invent new ways of managing what have become more diverse and very complex institutions. Therefore it comes as no surprise that the effectiveness of organisations and leaders' role in those organisations have been sources of study in both business and education sectors (Varner, 2002, p. 23). Not only will leaders across the higher education spectrum need new skills and new ways of thinking, but leaders themselves will have to act differently in an ever-changing environment in order to lead employees resourcefully. The role that effective leadership could play in defining and shaping educational reform is emerging as a central theme in change management literature (Retallick \& Fink, 2002, p. 91). However, ineffective and inefficient leadership has been identified by various authors as one of the major weaknesses of South African higher education, a fact that affects its transformation adversely (Badat, 2002; Cloete, Bunting \& Kulati, 2000; Council on Higher Education, 2000; Jansen, 2002, 2004; Kotecha, 2003; Seale, 2004).
This widespread acceptance of the need for effective leadership to shape institutional transformation in education and elsewhere has led to an extensive reconsideration of the definition of leadership and the personal attributes or abilities that underlie effective leadership. Goleman (1998, p. 312) argues that the skills and capabilities that will be needed by leaders in future will be radically different from those valued today. According to Zaccaro et al. $(2004$, p. 104) the role that personal attributes play in predicting leadership success will become more prominent as leadership situations become more complex and varied.

Given the increased recognition of the importance of emotions in leadership literature, the question arises whether the concept of emotional intelligence, measured as a set of abilities, might provide insight into the difference between outstanding and below par levels of leadership performance.

According to Mayer, Salovey and Caruso (2004, pp. 209-210), individuals with a high emotional intelligence might be more skilful in motivating people to achieve goals, aims and missions. Zaccaro et al. (2004, p. 116) assert that "because emotions are essential self-information, their accurate appraisal is crucial for effective self-regulation in the context of leadership". Emotions convey information about relationships and therefore people with a high emotional intelligence might be more socially effective than others in certain respects (Mayer, Salovey \& Caruso, 2000, p. 396). However, while research on emotional intelligence has progressed significantly since its inception, few academic studies have been conducted that explicitly examine its possible relationship with effective leadership.

Concurrent with the increase of interest in matters related to emotional intelligence in recent years, there has been an upsurge of interest in the area of cognitive psychology. Concepts such as "thinking style preference", "hemispheric specialisation", "brain-dominance" and "left-brain; right-brain thinking" have entered the vocabulary of cognitive psychologists to an ever-increasing extent (McAdam, 2002, p. 226). According to Herrmann $(1995,1996)$, preference for either right- or left- brain hemispheric cognitive style determines an individual's learning 
style and behaviour patterns as well as leadership style (Varner, 2002). How leaders assess situations, make decisions and apply leadership strategies are presumed to be influenced by their preferred thinking style controlled by functions said to be located in cortical and limbic structures within the brain. Such styles are thought to affect a range of management behaviours including the quality of problem analysis, decision making, leadership and change strategies of leaders and of groups (Sadler-Smith, 2004, p. 155).

It appears crucial to conduct research on the relationship between thinking style preference (TSP), emotional intelligence (EI) and effective leadership, since knowledge regarding these issues may contribute to significant advances in leadership training and development programmes as well as the ability to select potentially effective leaders. This relationship has yet to be examined because reliable and valid ability measures of EI have only emerged recently. Many of the claims in literature relating to the predictive value of EI lack the scientific evidence to support these assertions (Day \& Carroll, 2004, p. 1444). Furthermore, a lack of empirical research exists in cases where the relationship between effective leadership and thinking style preference has been investigated.

The Neethling Brain Preference Model, the ability model of emotional intelligence by Mayer and Salovey (1997) and the transformational leadership model by Kouzes and Posner (1987) provide the conceptual framework from which the researchers will examine the possible relationship between the concepts referred to and each will be discussed briefly.

\section{Brain hemisphericity or dominance and thinking style}

Thinking style preferences refer to the way in which individuals approach challenges and problems (Herrmann, 1996, p.16). Four distinct preferences can be distinguished, partly based on the specific hemisphere of the brain that the individual primarily uses (Herrmann, 1996, p.23; Neethling, 2005). Brain dominance or hemisphericity and separate cognitive processing styles or thinking styles can be identified in each individual, as demonstrated by using electroencephalographic (EEG) techniques (Ornstein, 1978).

The general notion of left- and right- brain dominance ("hemispheric preference" theory) is well established and has been substantiated by several researchers (Berk, 1989; Edwards, 1979; Gazzagnia, 1998; Herrmann, 1988; Kolb, 1983, Ornstein, 1997; Sperry, 1968). According to Springer and Deutsch (1993, p. 6), Sperry's split-brain studies proved that, although each hemisphere is capable of perceiving, learning, remembering and feeling independently of the other, there are significant differences in the way in which each hemisphere deals with incoming information. Gazzagnia (1998, p. 35) agrees: "The two hemispheres control vastly different aspects of thought and action. Each half has its own specialization and thus its own limitations and advantages". This theory proves that individuals' physical and intellectual abilities and their ability to solve problems are strongly influenced by the individual's preference to apply one part of the brain as opposed to the other.

Although the "hemispheric preference" theory has been criticised (e.g. Hines, 1987; Levy, 1985), evidence has been found to support the view of two radically different ways of thinking (Entwistle, 1981; Hayes \& Allison, 1998; Miller, 1987, 1991). Furthermore, evidence for the validity of the theoretical constructs underlying this dimension does exist (Beyler \& Schmeck, 1992). However, according to Leonard and Strauss (1997), the categorisation in left- and right-brained thinking is more powerful metaphorically than it is accurate physiologically. Not all assumed left-brained functions are actually located in the left, and the same is true for the assumed right-brained functions.

Herrmann's (1996, p.18) analysis of the work of Ornstein, Sperry and, more specifically, the triune brain model of Paul MacLean, provided evidence that the notion of a simple division between left- and right-brain specialisation was inadequate and that the limbic system also needs to be factored in if one wants to understand the experiential and thinking processes of the brain. Herrmann's (1996) research gave impetus to the development of his whole brain model reflecting the four types of thinking styles we find in people (i.e. cerebral left, cerebral right, limbic left, and limbic right). Two quadrants represent the two halves of the cerebral cortex and the other two represent the limbic system (Herrmann, 1996, p. 15). The cerebral mode is the cognitive, intellectual part of our thinking processes and the limbic mode is the structured visceral and emotional part of our thinking processes (Herrmann, 1995, p. 40). The appropriateness of the emotional response can also be influenced by the left limbic system (Gorovitz, 1982; Herrmann, 1995; Springer, 1981).

According to Herrmann (1995, 1996), a preference for the left cerebral mode means that a person favours activities that involve logical, analytical, fact-based information. A preference for the left limbic mode implies a linear approach to activities and favours organised, sequential, planned and detailed information. People with a left limbic mode preference are conservative in their actions and like to keep things as they are. A preference for the processes of the right limbic mode indicates favouring information that is interpersonal feelingbased and involves emotion. A preference for the processes of the right cerebral mode is mainly characterised by a holistic and conceptual approach in thinking. Herrmann $(1995$, p. 42) points out that although each hemisphere is specialised in a different way, the physical connections secure integrated brain activity.

Research suggests that brain hemisphericity impacts upon individuals' leadership style and various research studies (referred to in Toth, 1992-93) have highlighted the need to study leadership in relation to brain hemisphericity.

\section{Defining emotional intelligence (EI)}

Notwithstanding its conceptual origins (Salovey \& Mayer, 1990), but consistent with its early stage of empirical development, there is currently no universally accepted definition for EI. While several alternative models of this construct exist, the three that have generated the most interest in terms of research and application are the theories of Bar-On (1997), Goleman (1995) and Salovey \& Mayer (1990). Salovey and Mayer (1990) conceptualise EI as a cognitive ability that involves the processing of emotion, whereas alternative models define EI in terms of behaviours and skills, including stress management skills (such as stress tolerance and impulse control), self-management skills (such as self-control, conscientiousness and adaptability), as well as social skills (such as conflict management, leadership and communication) (Bar-On, 2000; Bar-On, Brown, Boyatzis, Goleman \& Rhee, 2000; Goleman, 1998; Higgs \& Dulewicz, 1999; Kirkaldy \& Thome, 2000). However, all these theories seek to understand how individuals perceive, understand, utilise and manage emotions in an effort to predict and promote personal effectiveness (Emmerling \& Goleman, 2003, p. 12).

Tasks that tap into the various abilities that underlie emotional intelligence are likely to have more validity than self-report measures (Mayer, DiPaolo \& Salovey, 1990), therefore Salovey and Mayer's cognitive processing model of EI constituted the theoretical basis for this construct in this study. According to Mayer and Salovey (in Mayer et al., 2000, p. 401), EI refers to "the ability to perceive and express emotions, assimilate emotions 


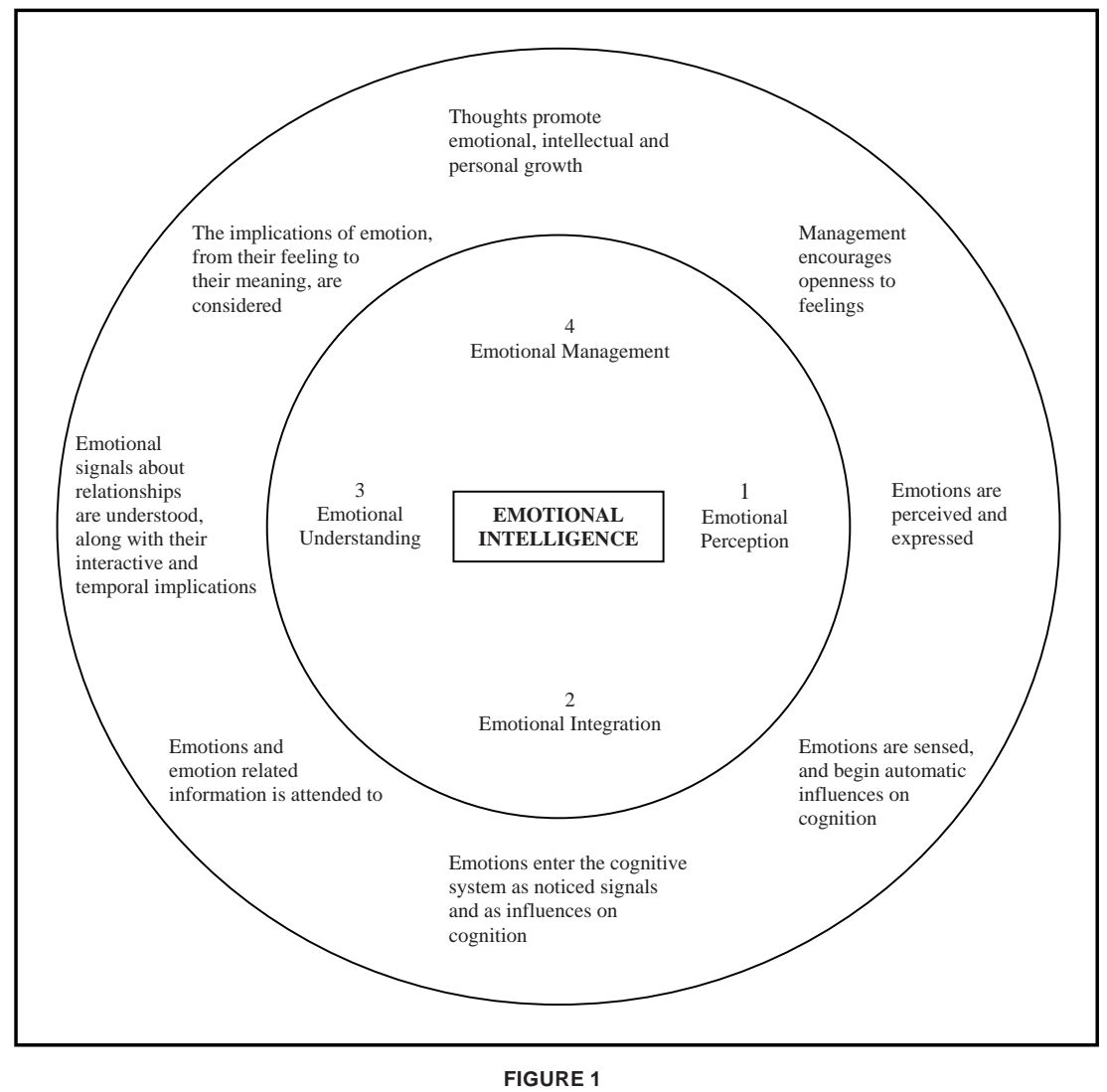

Mayer and Salovey's (1997) Four-Branch Model of Emotional Intelligence

in thought, understand and reason with emotion, and regulate emotion in self and others". Mayer and Salovey's (1997) model presents emotional intelligence as having four branches ranging from the most basic psychological processes (i.e. identifying and using emotions) to higher level mechanisms (i.e. understanding and managing emotions). The four different abilities within this model, which Mayer and Salovey refer to as branches, include a) perceiving emotion, b) using emotion to facilitate thought, c) understanding emotion, and d) managing emotions (Caruso, Mayer \& Salovey, 2002, pp. 306-307). A depiction of this fourbranch model is illustrated in Figure 1, which outlines the four branches and the corresponding stages in emotion processing associated with each branch.

\section{The Kouzes and Posner model of transformational leadership}

Despite the absence of a universally agreed upon definition of leadership, the literature on effective leaders seems to suggest that they tend to be "transformational" rather than "transactional" (Harris, Day, Hopkins, Hadfield, Hargreaves \& Chapman, 2003, p. 29). According to Higgs (2002, p. 199), the current emphasis on leadership relates to the ability of an organisation to manage and deliver significant organisational transformation.

Transformational leadership includes the following four facets: idealised influence, inspirational motivation, intellectual stimulation and individualised consideration (Bass, 1985, 1998; Bass \& Avolio, 1993). Apart from being linked with organisational performance, transformational leadership predicts higher ratings of subordinates' satisfaction with, and trust in leadership, higher group performance (Keller, 1995) and employees' emotional commitment to organisations (Barling, Slater \& Kelloway, 2000, p.157). Furthermore, the development of an emotional attachment (Bass, 1985; Bass, 1998; Yammarino \& Bass, 1990) that revolves "between those who choose to lead and those who decide to follow" is a fundamental part of the transformational leadership theory (Kouzes \& Posner, 1993, p. 1). Mandell and Pherwani (2003) found that level of EI (as measured by the Bar-On Emotions Quotient Inventory) was significantly related to transformational leadership style $(\mathrm{R}=0.50)$. The transformational leader is also "likely to be more pro-active than reactive, more innovative in ideas and less inhibited in ideational search for solutions" (Bass, 1985, p. 38).

Kouzes and Posner's (1987) transformational leadership model constituted the conceptual framework for the study, comprising five key transformational leadership behaviours. Kouzes and Posner (2001) suggest that successful transformational leaders demonstrate five distinct practices of leadership comprising the following ten strategies, which outstanding leaders use to affect employees' and organisational performance:

Practice one: Challenging the process:

- Search for opportunities

- Experiment and take risks

Practice two: Inspiring a shared vision:

- Envision the future

- Enlist others

Practice three: Enabling others to act:

- Foster collaboration

- Strengthen others

Practice four: Modelling the way:

- Set an example

- Achieve small wins

Practice five: Encouraging the heart:

- Recognise individual contributions

- Celebrate accomplishments

This model has been used extensively to assess leadership behaviours across a variety of organisations, disciplines and 
demographic backgrounds (Kouzes \& Posner, 1987). In the current study the researchers regarded effective leaders as those who demonstrated these five practices of transformational leaders.

\section{Aims of the research}

The aims of the research included the following:

a. Investigating ways in which thinking style preference and emotional intelligence are related to leadership effectiveness in the university context described in this article to determine whether EI and TSP can be used to predict leadership effectiveness.

b. Investigating the relationship between the thinking style a leader prefers and the impact thereof on leadership effectiveness as measured by the LPI.

c. Investigating whether either thinking style preference or ability-based emotional intelligence might predispose leaders to demonstrate transformational leadership behavioural patterns which could result in more effective leadership.

d. Our ultimate aim was to provide guidelines in terms of guidance and direction with regard to the design and delivery of management development programmes. No distinction is made between the terms leader and manager as the study only concerns formal leaders (that is, managers in higher education).

\section{Hypotheses}

Hypotheses were that:

a. scores between emotional intelligence, thinking style preference and leadership effectiveness for all groups combined would be correlated;

b. scores between emotional intelligence and leadership effectiveness for management level would be correlated;

c. scores between emotional intelligence and thinking style preference for all management levels would be correlated

d. a combination of biographical data, NBPP and EI scores (independent variables) would best predict facets of the LPI scores (dependent variables).

\section{RESEARCH DESIGN}

\section{Approach}

Quantitative (QUAN) methods were used in this study. This mode of inquiry (non-experimental) was descriptive because it allowed researchers to assess the nature of existing conditions in order to predict leadership behaviour (McMillan \& Schumacher, 2001, p. 33). More specifically, we conducted a survey to assess the thinking style preferences, emotional intelligence and leadership effectiveness of participants in a university context.

\section{Participants}

All staff members in management positions $(\mathrm{N}=204)$ at a higher education institution were approached to participate in the project. A total of $138(68 \%)$ completed all three assessments (93 males and 45 females; mean age $=46.0$ years). Of these participants $12.3 \%$ (17) held a senior management position (deans, chief directors), 80\% (111) were middle-level managers (heads of departments) and $7.2 \%$ (10) were supervisors (divisional heads). Anonymity in respect of their individual scores was guaranteed to all participants.

\section{Assessment instruments}

The instruments that were administered are described below.

\section{The Neethling Brain Preference Profile (NBPP)}

The first four-quadrant instrument to measure thinking preference was developed by Herrmann in 1981 (Herrmann, 1995). Under the supervision of Paul Torrance of the University of Georgia, Neethling analysed the responses of large groups of people to specific stimuli, identified four different thinking styles, and developed the Neethling Brain Preference Model and the Neethling Brain Preference Profile (NBPP) instrument to measure self-perceived thinking preferences (Neethling, 2005). Between 1988 and 1991, 2000 adults and 1500 pupils (with an equal distribution between 10 and 19 years of age) were included in research to develop Neethling's model. A question

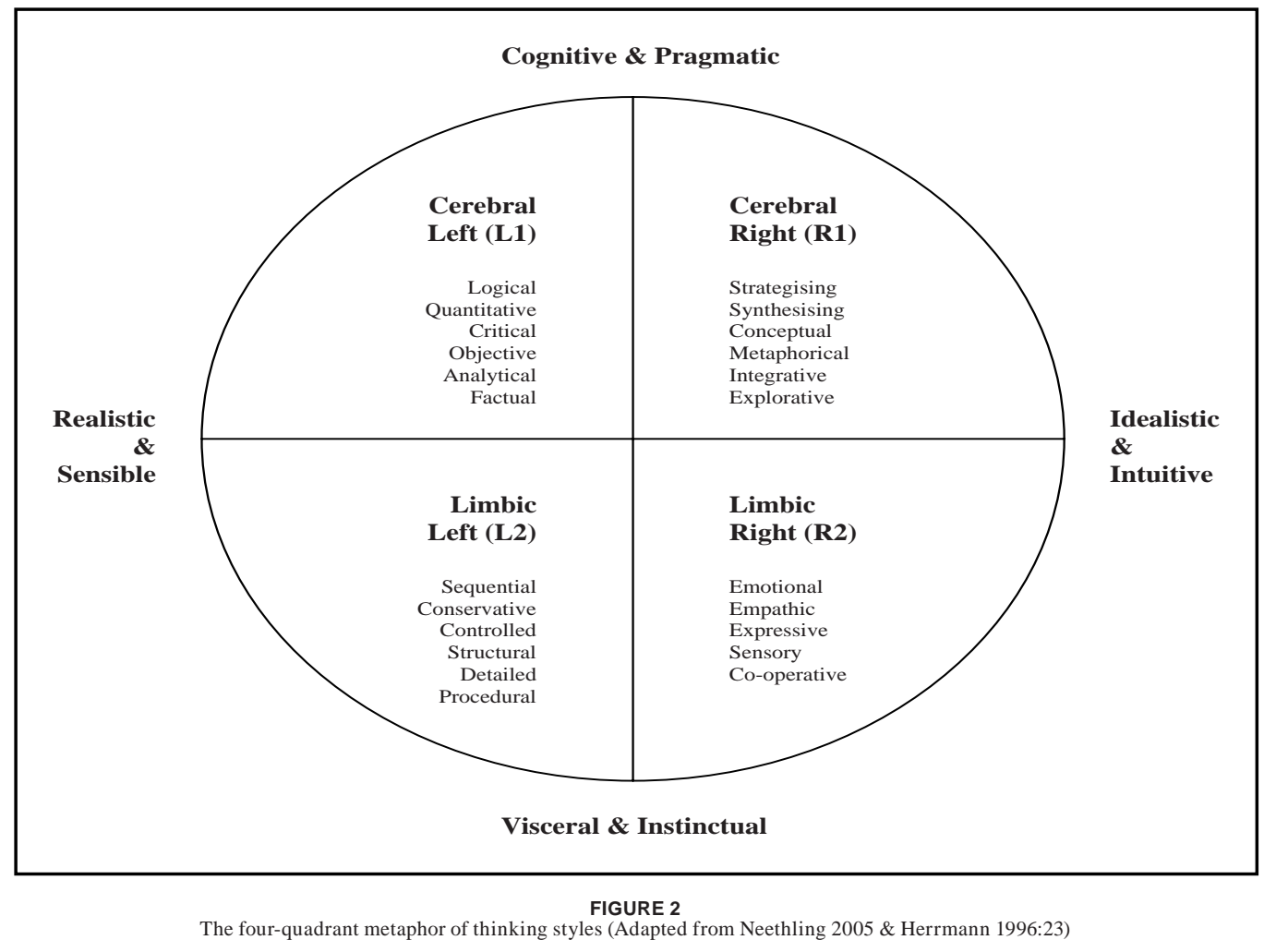


with four possible responses was posed to each of the subjects, who then had to arrange their personal thinking preferences from the strongest to the lowest. The choices for each question were based on the thinking processes belonging to the four different quadrants (i.e. L1, L2, R1 and R2). Neethling found that thinking preferences were divided randomly into four preference clusters, corresponding to the four quadrants as described in Figure 2. His four different thinking styles correspond well with the four-quadrant model of Herrmann. It should be noted that whereas the NBPP is an assessment instrument that quantifies the degree of individuals' preference for a specific mode of thinking, it provides no indication of "competencies"; instead, it reveals preferences and (at best) potential competencies.

The instrument indicates the different scores for the four quadrants of the thinking preference model. The scores reflect a participant's preference for making use of that particular quadrant in, among others, approaching challenges and making decisions. The NBPP can be completed on the internet and the results processed electronically. The scoring protocol results in a quantified measure of an individual's preference for each mental quadrant, which is then charted on a circular grid that provides a personalised visual metaphor. A numeric value is assigned to each quadrant, indicating the strength of preference for that quadrant. A score of 80 or higher on the NBPP is regarded as a "high" score.

Despite the fact that the ipsative nature of the NBPP (the fact that all scores add up to the same total) makes it unsuitable for some traditional measures of reliability and validity, limited analysis to investigate the psychometric integrity of the instrument revealed that the reliability of this instrument is acceptable. The test-retest reliability coefficients for the scales are as follows: $\mathrm{L} 1=0.880 ; \mathrm{L} 2=0.858 ; \mathrm{R} 1=0.8882 ; \mathrm{R} 2=0.921$ (Korf, 2004).

\section{The Mayer-Salovey-Caruso Emotional Intelligence Ability Test (MSCEIT)}

Emotional intelligence was measured by the Mayer-SaloveyCaruso Emotional Intelligence Ability Test, Version 2.0 (MSCEITV2.0; Mayer et al., 2000, 2002). The test contains 141 items that take approximately 35 minutes to complete. The test was largely informed by the emerging scientific understanding of emotions and their function and developed from an intelligence-testing perspective. Responses to the MSCEIT represent actual ability to solve emotional problems. Both the face and content validity of the MSCEIT have been proven to be adequate. Furthermore, the MSCEIT has a full-scale Cronbach alpha reliability of $\mathrm{r}=0.91$ or 0.93 (depending on whether expert or general consensus scoring is employed), with area reliabilities of $r=0.90$ for the experiential area and $r=0.85$ for the strategic area. The branch reliabilities range from $r=0.74$ to $r=0.89$. (Mayer et al., 2004, p. 202). Mayer, Salovey and Caruso (2002, p. 43) are of the opinion that "on the basis of the foregoing reliabilities, and our theory of EI, we believe the evidence for construct validity for the MSCEIT V2.0 is excellent, and that it already surpasses by far that of any other scale in the area of $\mathrm{EI}^{\prime \prime}$. More detailed information on the psychometric properties of this measure can be found in the MSCEIT user's manual (Mayer et al., 2002).

(At the time of writing this article, no validation studies have been conducted in the South African context.)

The test consists of eight tasks (faces, pictures, facilitation, sensation, changes, blends, emotional management and emotional relationships), which are divided into four branches or abilities. Analysis of the data provides the following scores reported here (Mayer et al., 2002, p. 17):
A total emotional intelligence score which provides a single overall index of the respondent's emotional intelligence. Two area scores, namely experiential EI (branch one and two) and strategic EI (branch three and four). Experiential EI refers to the ability to perceive emotional information and to use it to facilitate thought. Strategic EI refers to the ability to understand emotional information and use it strategically for planning and self-management. Four branch scores briefly described as follows (Caruso et al., 2002, p. 307):

The first branch, Identifying Emotions, indicates the respondent's ability to accurately perceive emotions in oneself, others and objects (e.g. art and stories) and to express emotions accurately. The second branch, Emotional Facilitation of Thought (or Using Emotions), serves as an indication of "the ability to use emotions to redirect attention to important events, to generate emotions that facilitate decision making, to use mood swings as a means to consider multiple points of view, and harness different emotions to encourage different approaches to problem solving". The third branch, Understanding Emotions, indicates the respondent's ability to understand how emotions combine to form more complex emotions and how emotions change from low to high intensity, as well as the ability to recognise the causes and consequences of emotions. The fourth branch, Managing Emotions, is the most advanced emotional ability and refers to the ability to be susceptible to feelings, either negative or positive, and to manage emotion in oneself and others, without necessarily suppressing negative emotions.

Raw scores for each of the tasks are automatically converted to standard scores $(m=100 ; s=15)$. Individual reports include descriptors for each of the four branches or abilities and tasks. Scores are categorised as Consider developing, Competent, or High performance.

\section{The Leadership Practices Inventory (LPI)}

In this study the five transformational leadership practices discussed earlier were assessed by means of the LPI (Kouzes \& Posner, 1988). Both the self and the observer forms of the LPI (Kouzes \& Posner, 1988) were used in the current study and both are 30-item leadership inventories. Each practice is measured by six behavioural descriptions, rated on a ten-point Likert Scale anchored by $1=$ Almost never and $10=$ Almost always. Both the reliability and validity (face validity and predictive validity) have been confirmed by validation studies over a ten-year period (Kouzes \& Posner, 1995). The participants completed the LPI Self form to rate their own behaviour while six observers were included for each participant. A total of 828 LPI Observer forms were sent out, of which 603 (73\% response rate) were completed and returned, a mean number of 4.4 observers per participant. The observers comprised participants' managers, subordinates and peers. Ratings from all observers for a given participant were averaged to develop mean LPI observer scores for that particular participant.

\section{Statistical analysis}

SAS version 9 (1996) was used to analyse the data. Correlations between LPI scores, NBPP scores as well as MSCEIT scores were firstly calculated. Stepwise regression analysis (Hosmer \& Lemeshow, 2000) was conducted to determine the variables and models that could be used to best predict $\left(p<0.5^{1}\right)$ facets of the Leadership Practices Inventory (dependent variables) through combinations of Biographical data, EI scores and NBPP scores (independent variables) of participants. The stepwise method was conducted on all participants $(\mathrm{N}=138)$ for the selection of predictor variables, with the significant level of $p=0.5$. The stepwise selection procedure provides a useful and effective way of independent variable selection (Hosmer \& Lemeshow, 
TABLE 1

Correlation coefficients indicating the correlation between emotional intelligence, thinking style preference and leadership effectiveness for all groups combined $(\mathrm{N}=138)$

\begin{tabular}{|c|c|c|c|c|c|}
\hline \multirow[b]{2}{*}{ MSCEIT } & \multicolumn{5}{|c|}{ LEADERSHIP PRACTICES INVENTORY (LPI) } \\
\hline & $\begin{array}{l}\text { Challenging the } \\
\text { process }\end{array}$ & $\begin{array}{l}\text { Inspiring a } \\
\text { shared vision }\end{array}$ & $\begin{array}{l}\text { Enabling others } \\
\text { to act }\end{array}$ & $\begin{array}{l}\text { Modelling the } \\
\text { way }\end{array}$ & $\begin{array}{l}\text { Encouraging the } \\
\text { heart }\end{array}$ \\
\hline \multicolumn{6}{|l|}{ MSCEIT } \\
\hline Age & $0.18^{*}$ & $0.26^{\star}$ & ns & ns & ns \\
\hline MSCEIT Total & ns & ns & ns & ns & ns \\
\hline \multicolumn{6}{|l|}{ Experiential EI } \\
\hline Identifying emotions & ns & ns & ns & ns & ns \\
\hline Using emotions & ns & ns & ns & ns & ns \\
\hline \multicolumn{6}{|l|}{ Strategic EI } \\
\hline Understanding emotions & ns & ns & ns & ns & ns \\
\hline Managing emotions & $0.21^{\star}$ & $0.19^{*}$ & ns & ns & ns \\
\hline \multicolumn{6}{|l|}{ Thinking Style Preference } \\
\hline Cerebral left (L1) & $-0.25^{\star}$ & $-0.20^{*}$ & ns & ns & ns \\
\hline Cerebral right (R1) & $0.34^{\star}$ & $0.27^{*}$ & $0.19^{*}$ & ns & ns \\
\hline Limbic left (L2) & $-0.25^{\star}$ & $-0.21^{\star}$ & ns & ns & ns \\
\hline Limbic right (R2) & ns & ns & ns & ns & ns \\
\hline Cerebral mode $(\mathrm{L} 1+\mathrm{R} 1)$ & $0.24^{*}$ & ns & ns & ns & ns \\
\hline Left Brain mode $(\mathrm{L} 1+\mathrm{L} 2)$ & $-0.29 *$ & $-0.24^{*}$ & $-0.22^{*}$ & ns & ns \\
\hline Limbic Mode (L2 + R2) & $-0.23^{*}$ & ns & ns & ns & ns \\
\hline Right Brain mode (R1 + R2) & $0.29 *$ & $0.24^{\star}$ & $0.22^{\star}$ & ns & ns \\
\hline
\end{tabular}

\section{${ }^{*} p \leq 0.05$}

ns $=$ not significant

2000). The Stepwise selection method (SAS, 1996) was used to determine the relevant variables from a number of identified variables (biographical variables, EI and thinking preference styles; independent variables) that may be used to predict leadership effectiveness.

\section{RESULTS}

Pearson product moment correlation coefficients were calculated to explore the extent to which facets of emotional intelligence, thinking style preference and leadership effectiveness (all groups combined: Table 1; managers: Table 2) are related.

Stepwise regression analyses were conducted for each of the five practices of effective leaders as the dependent variable and demographic variables, the four thinking preferences measured by the NBPP as well as the four abilities of emotional intelligence with its respective tasks measured by the MSCEIT as potential predictors (independent variables). Regression analysis was also conducted for each of the EI abilities as the dependent variable and the four thinking preferences as well as a combination thereof, as the potential predictors (independent variables).

From Table 1 it is evident that whereas age emerged as a significant predictor in the case of Challenging the process and Inspiring a shared vision, no significant correlation could be found between the EI total score and any one of the five leadership practices for all management levels combined. However, in the case of managers, statistically significant relationships were found between components of the LPI and the EI sub-scales. Managing or regulating emotions was the only EI ability that significantly correlated positively with Challenging the process $(p<0.05)$ and Inspiring a shared vision for all management levels combined.

Inspection of Table 1 also reveals a statistically significant positive correlation between the individual Cerebral right (R1) thinking style preference as well as the combined Right-brain modes ( $R 1$ and $R 2$ ) and the following three leadership practices: Challenging the process, Inspiring a shared vision and Enabling others to act. Conversely, a statistically significant negative relationship emerged between the combined Left-brain mode (L1 and L2) and these three leadership practices. Furthermore a statistically significant negative relationship emerged between the two left-brain thinking style preferences individually (L1 and L2) and Challenging the process and Inspiring a shared vision. Whereas the combined Limbic mode (L2 and R2) correlated negatively with the leadership practice Challenging the process, the combined Cerebral mode (L1 and R1) correlated statistically significantly positive with Challenging the process.

Inspection of Table 2 indicates positive correlations between the EI ability Managing emotions and the Leadership abilities Challenging the process and Inspiring $a$ shared vision, and between the Strategic emotional intelligence score and Challenging the process.

TABLE 2

Correlation coefficients indicating the correlation between emotional intelligence and leadership effectivenes for the management level $(\mathrm{N}=111)$

\begin{tabular}{|c|c|c|c|c|c|}
\hline \multirow[b]{2}{*}{ MSCEIT } & \multicolumn{5}{|c|}{ LEADERSHIP PRACTICES INVENTORY (LPI) } \\
\hline & $\begin{array}{l}\text { Challenging the } \\
\text { process }\end{array}$ & $\begin{array}{l}\text { Inspiring a shared } \\
\text { vision }\end{array}$ & $\begin{array}{l}\text { Enabling others } \\
\text { to act }\end{array}$ & $\begin{array}{l}\text { Modelling the } \\
\text { way }\end{array}$ & $\begin{array}{l}\text { Encouraging the } \\
\text { heart }\end{array}$ \\
\hline MSCEIT Total & 0.18 & 0.09 & 0.05 & 0.05 & 0.05 \\
\hline Experiential El & 0.12 & 0.01 & -0.02 & -0.03 & 0.00 \\
\hline Identifying emotions & 0.04 & -0.08 & -0.08 & -0.04 & -0.05 \\
\hline Using emotions & 0.10 & 0.04 & 0.04 & 0.00 & 0.01 \\
\hline Strategic El & $0.21^{*}$ & 0.18 & 0.12 & 0.13 & 0.12 \\
\hline Understanding emotions & 0.15 & 0.11 & 0.11 & 0.08 & 0.10 \\
\hline Managing emotions & $0.21^{*}$ & $0.19^{*}$ & 0.08 & 0.14 & 0.10 \\
\hline
\end{tabular}


TABLE 3

Correlation coefficients indicating the correlation between emotional intelligence and thinking style preference for all management levels combined $(\mathrm{N}=111)$

\begin{tabular}{|c|c|c|c|c|c|c|c|c|}
\hline & $\begin{array}{l}\text { CEREBRAL } \\
\text { LEFT (L1) }\end{array}$ & $\begin{array}{l}\text { CEREBRAL } \\
\text { RIGHT (R1) }\end{array}$ & $\begin{array}{l}\text { LIMBIC } \\
\text { LEFT (L2) }\end{array}$ & $\begin{array}{l}\text { LIMBIC } \\
\text { RIGHT (R2) }\end{array}$ & $\begin{array}{l}\text { CEREBRAL } \\
\text { MODE (L1 + R1) }\end{array}$ & $\begin{array}{l}\text { LEFT BRAIN } \\
(\text { L1 + L2) }\end{array}$ & $\begin{array}{l}\text { LIMBIC MODE } \\
\text { (L2 + R2) }\end{array}$ & $\begin{array}{l}\text { RIGHT BRAIN } \\
(\mathrm{R} 1+\mathrm{R} 2)\end{array}$ \\
\hline MSCEIT & ns & ns & ns & ns & ns & ns & ns & ns \\
\hline El Total Score & ns & ns & ns & ns & ns & ns & ns & ns \\
\hline Experiential El & ns & ns & ns & ns & ns & ns & ns & ns \\
\hline Identifying emotions & ns & ns & ns & ns & ns & ns & ns & ns \\
\hline Using emotions & ns & ns & ns & ns & ns & ns & ns & ns \\
\hline Strategic EI & ns & ns & ns & ns & ns & ns & ns & ns \\
\hline Understanding emotions & ns & $0.22^{*}$ & ns & ns & $0.20^{*}$ & ns & ns & ns \\
\hline Managing emotions & ns & ns & ns & ns & ns & ns & ns & ns \\
\hline
\end{tabular}

${ }^{*} p \leq 0.05$

ns $=$ not significant

TABLE 4

Stepwise regression model of facets of the Leadership Practices Inventory (dependent variables) and biographical data, NBPP and EI scores (independent variables) for all participants $(\mathrm{N}=138)$

\begin{tabular}{|c|c|c|c|c|c|c|}
\hline \multirow[b]{2}{*}{ FIELD } & & \multirow[b]{2}{*}{ Parameter Estimate } & \multicolumn{2}{|c|}{ COEFFICIENT OF DETERMINATION } & \multirow[b]{2}{*}{$F$} & \multirow[b]{2}{*}{$\mathbf{p}$} \\
\hline & & & Partial $\mathbf{R}^{2}$ & Model/ Cumulative $\mathbf{R}^{2}$ & & \\
\hline \multirow{2}{*}{$\begin{array}{l}\text { Challenging the process } \\
\text { (Observer Score) }\end{array}$} & Qualification level & -2.97 & 0.05 & 0.05 & 6.47 & $0.0075^{\star}$ \\
\hline & Strategic El & 0.15 & 0.05 & 0.10 & 7.17 & $0.0084^{\star}$ \\
\hline $\begin{array}{l}\text { Inspiring a shared vision } \\
\text { (Self Score) }\end{array}$ & Age & 0.17 & 0.03 & 0.03 & 4.36 & $0.0386^{*}$ \\
\hline \multirow{3}{*}{$\begin{array}{l}\text { Inspiring a shared vision } \\
\text { (Average Observer Score) }\end{array}$} & Qualification level & -2.21 & 0.03 & 0.03 & 3.68 & $0.0573^{*}$ \\
\hline & Age & 0.17 & 0.05 & 0.08 & 7.34 & $0.0218^{*}$ \\
\hline & Managing emotions & 0.11 & 0.03 & 0.11 & 4.54 & $0.0328^{*}$ \\
\hline \multirow[t]{2}{*}{ TotalSelf } & Age & 0.60 & 0.03 & 0.03 & 3.43 & 0.0664 \\
\hline & Strategic El & 0.47 & 0.02 & 0.05 & 3.21 & 0.0756 \\
\hline Total Self + Observers & Age & 0.97 & 0.03 & 0.03 & 4.44 & $0.0370^{*}$ \\
\hline \multirow{2}{*}{ Challenging the process } & Limbic left & -0.45 & 0.03 & 0.03 & 3.00 & $0.0583^{*}$ \\
\hline & Limbic right & -0.44 & 0.09 & 0.12 & 7.26 & $0.0564^{*}$ \\
\hline \multirow{3}{*}{ Understanding emotions } & $\begin{array}{l}\text { Combined right brain modes } \\
(\mathrm{R} 1+\mathrm{R} 2)\end{array}$ & 0.25 & 0.02 & 0.02 & 2.22 & 0.1390 \\
\hline & $\begin{array}{l}\text { Combined limbic modes } \\
\text { (L2 + R2) }\end{array}$ & -0.21 & 0.03 & 0.03 & 3.40 & 0.0680 \\
\hline & $\begin{array}{l}\text { Combined cerebral modes } \\
(\mathrm{L} 1+\mathrm{R} 1)\end{array}$ & 0.23 & 0.04 & 0.04 & 4.42 & $0.0380^{*}$ \\
\hline Perceiving emotions & $\begin{array}{l}\text { Combined cerebral modes } \\
(L 1+L 2)\end{array}$ & -0.13 & 0.02 & 0.06 & 2.35 & 0.1282 \\
\hline
\end{tabular}

${ }^{*} \mathrm{p}<0.05$

*For the purposes of our analysis, the following criteria were applied (Ellis, 2005):

a. $R^{2}<0.13$ : $\quad$ Small effect size

$\begin{array}{ll}\text { b. } 0.13 \leq R^{2} \leq .0 .25: & \text { Medium effect size } \\ \text { c. } R^{2}>0.25: & \text { Large effect size }\end{array}$

Inspection of Table 3 shows a statistically significant correlation between the Cerebral right (R1) as well as the combined Cerebral mode (L1 and R1) thinking preferences and the EI ability Understanding emotions (all management levels combined).

Inspection of Table 4 reveals that qualification level and Strategic EI score emerged as statistically significant predictors $(p<0.05)$ in the case of Challenging the process (Observer score). Whereas age emerged as the only significant predictor $(p<0.05)$ of Inspiring a shared vision, three variables, namely, qualification, age and Managing emotions emerged as significant predictors $(p<0.05)$ in the case of Inspiring a shared vision (mean of Observer score). Whereas age and Strategic EI score emerged as significant predictors in the case of Total Self (i.e. total Self score on the LPI), age emerged as the only significant predictor in the case of Total Average (total score on the LPI, id est., sum of scores of Self and Others). Lastly, it is evident from Table 4 that the Combined Cerebral mode $(L 1+R 1)$ of thinking emerged as significant predictors of the EI ability, Understanding emotions. The Cerebral left-brain mode (L1) and the Cerebral right-brain mode (R1) of thinking emerged as statistically significant predictors of the leadership factor, namely Challenging the process.

\section{DISCUSSION}

Age emerged as a significant predictor variable in respect of all three leadership practices, as well as Total Self (average of participant's evaluation of him-/herself on all five leadership practices). This finding supports the view of Kakabadse (in Oshagbemi, 2004, p. 23) that more mature leaders, both in attitude and years, are better performers; that age differences exist in both effectiveness and behaviour (referred to in Oshagbemi, 2004, p. 17); and that older and younger managers have distinct leadership styles (Oshagbemi, 2004). Qualification level also emerged as a significant predictor variable in respect of two leadership practices. This finding was expected due to the dynamic relationship that exists between the leader and the organisational context (Dulewicz \& Higgs, 2005). Within the context of a higher education institution, the qualification level of the leader might add to his/her credibility and as a result, impact on effectiveness as a leader. Strategic EI, too, emerged as a significant predictor variable in respect of one leadership practice, and Total Self.

According to Gill (referred to in Oshagbemi, 2004, p. 21) selfreports may be a reliable and useful method of data collection and the risk of bias overestimated. From the aforementioned it seems logical to deduce that older leaders, and, to some extent, higher qualified ones, may tend to be more effective managers. Furthermore we have found some evidence that those leaders who show evidence of a Strategic EI also appear to be more effective in dealing with subordinates. The significant negative relationship between the Limbic left (L2) and the Limbic right mode (R2) thinking style preference and Challenging the process 
is in line with the following (Mandell \& Pherwani, 2003, p. 391) statement: "Transformational leaders appear to be more behavioural and less emotional when dealing with stress and conflict". This effect is expected as people who prefer the L2 thinking mode are conservative in their actions and like to maintain the status quo. People who prefer the $R 2$ thinking mode are sensitive to people's feelings and tend to avoid conflict. This negative impact on Challenging the process also confirms the statement by Bass $(1985$, p. 38) that transformational leaders are "likely to be more pro-active than reactive, more innovative in ideas and less inhibited in ideational search for solutions". It is probably essential for leaders to be less emotional, since creativity in organisations is affect-laden, and involves coming up with something new and challenging the status quo which often creates anxiety and uncertainty (Zhou \& George, 2003, p. 546). Based on this finding, a dominant Left-brain mode (L1 and R1) thinking preference amongst leaders might sometimes tend to hamper innovation as well as the transformation agenda within the higher education sector.

The fact that the combined Cerebral modes (L1 and R1) thinking preference emerged as significant predictor variables in respect of managers' ability to understand and reason about emotions, provides some evidence that it may be useful to dwell on these thinking preferences during emotional intelligence training and development of managers, especially those with identified underdeveloped left-brain or limbic mode thinking preferences.

In the first section of this article, we surmised that emotional intelligence as well as thinking style preference might be an important determinant of leadership behaviour. To investigate this hypothesis, we examined the possible relationship between individual thinking style preference, emotional intelligence and effective leadership at a higher education institution. Multiple regression analysis revealed that some facets of EI (as measured by the MSCEIT) predict leadership effectiveness (measured by the LPI) statistically, but not practically, significantly.

Summarised, the findings of the current study suggest that EI as measured by the MSCEIT may in some way be linked to some of the abilities of effective leaders measured by the LPI and that facets of emotional intelligence may be useful predictors of transformational leadership behaviours (Herbst, Maree \& Sibanda, 2006). However, since the effect sizes were small throughout, our results and (provisional) conclusions need to be interpreted with extreme caution.

\section{Recommendations}

Although the type of research referred to in this article was explorative and our investigation in its early stages, it provides an additional perspective to the body of research regarding the emotional and cognitive attributes that facilitate effective leadership within the context of a higher education institution. Some areas for future investigation might include the relationship between managers' emotional intelligence and thinking style preference and organisational cultures which could provide a more complete picture of the cognitive and emotional dynamics that constitute effective leadership within higher education institutions. Although current research supports the idea that managers can be trained to use transformational leadership behaviours (Barling et al., 2000; Kouzes \& Posner, 1995), future research should also focus on the extent to which these cognitive and emotional intelligence abilities can be developed through training and development programmes. As evidence exists both for and against the ability for emotional competencies to be developed (referred to in Emmerling \& Goleman, 2003), it is important that future research determine the extent to which such learning may occur before an organisation places considerable funds in a development programme. It might be that selecting managers on the basis of their thinking style preference and EI may prove to be more effective than attempting to develop these personal attributes later on. Furthermore, although considerable research has been conducted on the role of thinking style preference and EI in business, there is a lack of research examining the role thereof on leadership effectiveness in higher education institutions, especially during periods of restructuring and change.

\section{Limitations of the study}

The results are exploratory in nature and require replication with a sample from a diverse range of industries across both private and public sectors. In addition, further research using alternative leadership models and frameworks would appear to be warranted.

\section{CONCLUSION}

Emotions, although omnipresent in human endeavours, have been marginalised consistently within mainstream educational research (Beatty, 2000). Insight into how thinking style preference and EI relates to effective leadership may increase our understanding of effective leadership and help develop potentially authoritative instruments for the selection, training and development of leaders, potentially enhancing organisational wellness and performance. Researchers (in higher education and indeed elsewhere) can no longer afford to treat emotions as subordinate, insignificant or peripheral if we are to explore fully the underlying abilities and behaviours of effective leaders. Leadership comprises both intellectual and emotional facets and both these facets need to be attended to during the training of managers in order to equip them with sufficient leadership skills. In changing and unstable times such as ours, it is imperative to investigate the subtle interplay between cognitive and affective processes that impact on leadership skills in times of change. While we realise that the current study is only a small beginning, the results offer a potentially valuable glimpse of this largely uncharted territory, and add to our understanding of what constitutes meaningful exploration of the personal attributes or abilities of leaders capable of promoting transformation and organisational change. As researchers we believe that we are dealing with issues that can be described as "critical mass aspects", analysis of which could be utilised to enhance leadership effectiveness significantly.

\section{ACKNOWLEDGEMENTS}

The authors wish to thank Drs Kouzes and Posner for permission to use the LPI instrument, MP Mokilane for the statistical analysis, the TUT management for their support, and the respondents for taking part in the research. We also wish to thank the two anonymous reviewers for taking the time to make extremely helpful suggestions, which have contributed to the current article in a meaningful way.

\section{REFERENCES}

Badat, S. (2002). Transforming South African higher education, 1990-2003: Goals, policy initiatives and critical challenges and issues. Paper presented at the African Higher Education Partnership meeting, 16-18 March 2002, Nigeria. Retrieved July, 3, 2006, from the Word Wide Web: http://che.ac.za/ che_secretariat/ceo_papers/2003/SA-Transform_Dec2003. pdf

Barling, J. Slater, F. \& Kelloway, E.K. (2000). Transformational leadership and emotional intelligence: An exploratory study. Leadership and Organization Development Journal, 21(2), 157-161.

Bar-On, R. (1997). Bar-On Emotional Quotient Inventory. Toronto: Multi-Health Systems. 
Bar-On, R. (2000). Emotional and social intelligence: Insights from the Emotional Quotient Inventory. In Bar-On, R. \& Parker, J. D. (Eds.). The handbook of emotional intelligence. San Francisco: Jossey-Bass.

Bar-On, R., Brown, J.M., Kirkaldy, B.D. \& E.P. Thome. (2000). Emotional expression and implications for occupational stress: An application of the Emotional Quotient Inventory (EO-I). Personality and Individual Differences, 28, 1107-1118.

Bass, B.M. (1985). Leadership and performance beyond expectations. New York: Free Press.

Bass, B.M. (1998). Transformational leadership: Industry, military and educational impact. Mahwah, NJ: Erlbaum.

Bass, B.M. \& Avolio, B.J. (1993). Transformational leadership: A response to critiques. In M.M. Chermers \& R. Anyman (Eds.) Leadership theory and research: Perspectives and directions. New York: Free Press.

Beatty, B.R. (2000). The emotions of educational leadership: Breaking the silence. International Journal of Leadership in Education, 3(4), 331-357.

Berk, L.E. (1989). Child development. Boston: Allyn \& Bacon.

Beyler, J. \& Schmeck R.R. (1992). Assessment of individual differences in preferences for holistic-analytic strategies: Evaluation of some commonly available instruments. Educational and Psychological Measurement, 52, 709-719.

Boyatzis, R.E., Goleman, D. \& Rhee, K.S. (2000). Clustering competence in emotional intelligence: Insights from the Emotional Competence Inventory. In Bar-On, R. \& Parker. J. D. A.. (Eds). The handbook of emotional intelligence. San Francisco: Jossey-Bass.

Caruso, D.R., Mayer, J.D. \& Salovey, P. (2002). Relation of an ability measure of emotional intelligence to personality. Journal of Personality Assessment, 79(2), 306-320.

Cloete, N., Bunting, I. \& Kulati, T. (2000). Leadership and institutional change in higher education. Pretoria: Centre for Higher Education Transformation (CHET).

Council on Higher Education (CHE). (2000). Report of the CHE's shape and size task team. Pretoria. Retrieved July, 3, 2006, from the World Wide Web: http://che.ac.za

Day, A.L. \& Carroll, S.A. 2004. Using an ability-based measure of emotional intelligence to predict individual performance, group performance, and group citizenship behaviours. Personality and Individual Differences, 36, 1443-1458.

Dulewicz, V. \& Higgs, M. (2004). Assessing leadership styles and organisational context. Journal of Managerial Psychology, 20(2), 105-123.

Edwards, B. (1979). Drawing on the right side of the brain. New York: St. Martin's Press.

Ellis, S.M. (2005). Personal communication with Professor JG Maree.

Emmerling, R.J. \& Goleman, D. (2003). Emotional intelligence: Issues and common misunderstandings. Retrieved April, 5, 2006, from the World Wide Web: http://eiconsortium.org

Entwistle, N.J. (1981). Styles of learning and teaching. Chichester: Wiley.

Gazzaniga, M.S. (1998). The split brain revisited. Scientific American, 279(1), 50-55.

Goleman, D. (1995). Emotional intelligence: Why it can matter more than IQ. New York: Bantam.

Goleman, D. (1998). Working with Emotional Intelligence. London: Bloomsbury.

Gorovitz, E.S. (1982). The creative brain II: A revisit with Ned Herrmann. Training and Development Journal, December, $75-88$

Harris, A., Day, C., Hopkins, D., Hadfield, M., Hargreaves, A. \& Chapman, C. (2003). Effective leadership for school improvement. New York: RoutledgeFalmer.

Hayes, J. \& Allison, C.W. (1998). Cognitive style and the theory and practice of individual and collective learning in organizations. Human Relations, 51, 847-871.

Herbst, H.H., Maree, J.G. \& Sibanda, E. (2006.) Emotional intelligence and leadership abilities. South African Journal of Higher Education, 20(5), 592-612.
Herrmann, N. (1995). The creative brain. Kingsport: Quebeccor Printing Group.

Herrmann, N. (1996). The Whole Brain Business Book. New York: McCraw-Hill.

Herrmann, N. (1988). The creative brain. Lake Lure, NC: Brain Books.

Higgs, M. \& Dulewicz, V. (1999). Making sense of Emotional Intelligence. Windsor: ASE.

Higgs, M. (2002). Do leaders need emotional intelligence? A study of the relationship between emotional intelligence and leadership of change. International Journal of Organisational Behaviour, 5(6), 195-212.

Hines, T. (1987). Left brain/right brain mythology and implications for management and training. Academy of Management Review, 12, 600-606.

Hosmer, D.W. \& Lemeshow, S. (2000). Applied logistic regression. New York: John Wiley.

Jansen, D. (2002). Seven major challenges facing higher education. Keynote Address delivered at the Council on Higher Education (CHE) Consultative Conference IV. Johannesburg.

Jansen, D. (2004). Race, education and democracy after ten years: How far have we come? Report prepared for the Institute for Democracy in South Africa (IDASA). Retrieved July, 3, 2006, from the World Wide Web: http://chet.org.za/issues/ raceedudemoc.doc

Keller, R.T. (1995). Transformational leaders make a difference. Journal of Research and Technology Management, 39, 41-44.

Kolb, D.A. (1983). Experiential learning: Experience as the source of learning and development. Englewood Cliffs, NJ: PrenticeHall.

Korf, L. (2004). Updated research report: Validity and reliability of the Neethling Brain Instrument. Unpublished report. Pretoria

Kotecha, P. (2003). Leadership, identity and the state in South African higher education. Paper presented at the Association of Commonwealth Universities Conference, Belfast, 31 August - 4 September 2003.

Kouzes, J.M. \& Posner, B.Z. (1987). The leadership challenge: How to get extraordinary things done in organizations. San Francisco: Jossey-Bass.

Kouzes, J.M. \& Posner, B.Z. (1993). Credibility: How leaders gain and lose it, why people demand it. California: Jossey-Bass.

Kouzes,J.M. \& Posner, B.Z. (1995). Development and validation of Leadership Practices Inventory. Educational and Psychological Measurement, 48, 483-496.

Kouzes, J.M. \& Posner, B.Z. (2001). The Leadership Practices Inventory (LPI). Facilitator's Guide 2nd edition. San Francisco: Jossey-Bass/Pfeiffer.

Leonard, D. \& Strauss S. (1997). Putting your company's whole brain to work. Harvard Business Review, 75, 111-121.

Levy, J. (1985). Right brain, left brain: Fact and fiction. Psychology Today, 19, 38-44.

Mandell, B. \& Pherwani, S. (2003). Relationship between emotional intelligence and transformational leadership style: A Gender Comparison. Journal of Business and Psychology, 17(3), 387-404.

Mayer, J.D., DiPaolo, M.T. \& Salovey, P. (1990). Perceiving affective content in ambiguous visual stimuli: A component of emotional intelligence. Journal of Personality Assessment, $54,772-781$

Mayer, J.D. \& Salovey, P. (1997). What is emotional intelligence? In P. Salovey \& D. Sluyter (Eds.). Emotional development and emotional intelligence: Implications for educators. New York: Basic Books.

Mayer, J.D., Salovey, P. \& Caruso, D.R. (2000). Models of emotional intelligence. In Sternberg, R.J. (Ed.). Handbook of human intelligence. New York: Cambridge.

Mayer, J.D., Salovey, P. \& Caruso, D.R. (2002). MSCEIT user's manual. Toronto, Canada: Multi-Health Systems.

Mayer, J.D., Salovey, P \& Caruso, D.R. (2004). Emotional Intelligence: Theory, findings, and implications. Psychological Inquiry, 15(3), 197-215. 
Mayer J.D. \& Salovey, P. (1995). Emotional intelligence and the construction and regulation of feelings. Applied and Preventative Psychology, 4, 197-208.

McAdam, N.A. (2002). Brain styles model of change responsiveness and distributed leadership in 21st century network organisations. International Journal of Organisational Behaviour, 5(7), 213-241.

McMillan, J.H. \& Schumacher, S. (2001). Research in education: A conceptual introduction (5th edition). New York: Addison Wesley Longman.

Mignot-Gérard, S. (2003). "Leadership" and "Governance" in the analysis of university organisations: Two concepts in need of de-construction. Higher Education Management and Policy, 15(2), 135-163.

Miller, A. (1987). Cognitive Styles: An integrated model. Educational Psychology, 7, 251-268.

Miller, A. (1991). Personality types, learning styles and educational goals. Educational Psychology, 11, 217-238.

Neethling, K. (2005). Practitioner Training Manual. Unpublished Manual. Pretoria.

Orstein, R. (1978). The split and the whole-brain. Human Nature, $1,76-83$.

Ornstein, R. (1997). The right mind: making sense of the hemispheres. New York: Harcourt Brace.

Oshagbemi, T. (2004). Age influences on the leadership styles and behaviour of managers. Employee Relations, 26(1), $14-9$.

Retallick, J. \& Fink, D. (2002). Framing leadership: Contributions and impediments to educational change. International Journal of Leadership in Education, 5(2), 91-104.

Sadler-Smith, E. (2004). Cognitive style and the management of small and medium-sized enterprises. Organization Studies, 25(2), 155-181.

Salovey, P. \& Mayer, J.D. (1990). Emotional intelligence. Imagination, Cognition and Personality 9(3):185-211.
SAS Institute Inc. (1996). SAS STAT User's Guide, Version 9, Cary, NC: SAS Institute.

Seale, O. (2004). Rooting for management capacity in South African higher education. Paper presented at the HESDA Staff Development Conference, 4 November 2004. Retrieved July, 3, 2006, from the World Wide Web: http://hesda.org. uk/activities/events/sdev2004/workshop7.doc

Sperry, R.W. (1968). Hemisphere disconnection and unity in conscious awareness. America Psychologist, 23(10), 723-733.

Springer, J. (1981). Brain/Mind and Human Resources Development. Training and Development Journal, August, 42-49.

Springer, S.P., \& Deutsch, G. (1993). Left brain, right brain. San Francisco: Freeman.

Toth, P.E. (1992-93). Brain hemispheric characteristics and leadership style of school superintendents. National Forum of Applied Educational Research Journal. Retrieved October, 12, 2006, from the World Wide Web: http:// nationalforum.com

Varner, J.P. (2002). The relationship between West Virginia school principals' self-perceived brain hemispheric cognitive styles/leadership styles and identified school of excellence. Unpublished dissertation. West Virginia University, Morgantown, West Virginia.

Yammarino, F.J. \& Bass, B.M. (1990). Transformational leadership at multiple levels of analysis. Human Relations, 43, 975-995.

Zaccaro, S.J., Kemp, C. \& Bader, P. (2004). Leader traits and attributes. In J. Antonakis, A.T. Cainciolo \& R.J. Sternberg (Eds.). The Nature of Leadership. California: Sage Publications.

Zhou, J. \& George, J.M. (2003). Awakening employee creativity: The role of leader emotional intelligence. The Leadership Quarterly, 14, 545-568. Retrieved February, 19, 2006, from the World Wide Web: http://sciencedirect.com 